\title{
A simplified human head finite element model for brain injury assessment of blunt impacts
}

\author{
M.H.A. Hassan ${ }^{1,2^{*}}$, Z. Taha ${ }^{1}$, I. Hasanuddin ${ }^{3}$, A.P.P.A. Majeed ${ }^{1}$, H. Mustafa ${ }^{4}$, and N. A. Othman ${ }^{5}$ \\ ${ }^{1}$ Innovative Manufacturing, Mechatronics and Sports Lab (iMAMS), Faculty of Manufacturing and Mechatronics Engineering Technology, Universiti \\ Malaysia Pahang, 26600 Pekan, Pahang, Malaysia \\ Phone: +6094245854; Fax: +6094245888 \\ 2 Faculty of Mechanical \& Automotive Engineering Technology, Universiti Malaysia Pahang, 26600 Pekan, Pahang, Malaysia \\ ${ }^{3}$ Department of Mechanical Engineering, Syiah Kuala University, Banda Aceh, Aceh, Indonesia \\ ${ }^{4}$ Faculty of Mechanical and Manufacturing Engineering, Universiti Tun Hussein Onn Malaysia, 86400 Parit Raja, Batu Pahat, Johor, Malaysia \\ ${ }^{5}$ Faculty of Electrical \& Electronics Engineering Technology,Universiti Malaysia Pahang, 26600 Pekan, Pahang, Malaysia
}

\begin{abstract}
Blunt impacts contribute more than $95 \%$ of brain trauma injuries in Malaysia. Modelling and simulation of these impacts are essential in understanding the mechanics of the injuries to develop a protective equipment that might prevent brain trauma. Various finite element models of human head have been developed, ranging from two-dimensional models to very complex three-dimensional models. The aim of this study is to develop a simplified threedimensional human head model with low computational cost, yet capable of producing reliable brain responses. The influence of different head-neck boundary conditions on the brain responses were also examined. Our model was validated against an experimental work on human cadaver. The model with free head-neck boundary condition was found to be in good agreement with experimental results. The head-neck joint was found to have a significant influence on the brain responses upon impact. Further investigations on the head-neck joint modelling are needed. Our simplified model was successfully validated against experimental data on human cadaver and could be used in simulating blunt impact scenarios.
\end{abstract}

ARTICLE HISTORY

Revised: $21^{\text {st }}$ Feb 2020

Accepted: $4^{\text {th }}$ Mar 2020

\section{KEYWORDS}

Human head;

finite element model;

brain injury;

blunt impact;

low computational cost.

\section{INTRODUCTION}

The fourth edition of the Malaysian National Trauma Database reported that the main mechanism of major trauma injuries are related to blunt trauma which accounts for $96.31 \%$ [1], in which $28.1 \%$ involves fatality. The head and neck were reported to be the most susceptible region towards the aforementioned mechanism at $85.36 \%$ [1]. Traumatic brain injuries (TBI) are not uncommon among the aforesaid percentile and similar trend was also reported in the UK, US as well as in China [2-4]. The underlying principles behind the mechanics of blunt TBI are still not well understood and in investigating this phenomenon, researchers in the past have conducted both experimental as well as computational studies.

Head impact tests were conducted on human cadavers to study its impact on the brain [5-8]. This involves hitting the cadaver's head with a padded impactor. Pressure sensors and accelerometers were placed at some locations on the cadaver's head to record the intracranial pressure and the head accelerations resulted by the impact. Nonetheless, this is a less favourable approach since it is almost impossible to measure several important parameters during the impact like the brain deformation parameters (von Mises stress and principle strain).

Mass-spring-damper models of head impact were also developed to estimate the head's and brain's acceleration induced by the head impact in sports [9-11]. However, this mathematical models only produces the kinematics of the brain (i.e. the linear and angular motion of the brain) due to head impact. Other important parameters such as brain deformation cannot be visualised or analysed. A more practical approach is to develop a three-dimensional finite element (FE) model of human head. A properly validated human head FE model will be very useful in analysing what is happening to the brain during a head impact.

The FE method is a numerical technique that is able to produce good approximate solutions that predicts the response of a physical system when subjected to external loads. Two dimensional (2D) modelling is often known for its simplicity and low computational cost, nonetheless, the solutions generated is less accurate than the much preferred three dimensional (3D) FE modelling that requires higher computational cost. Geometrically and constitutively accurate models are prerequisites in achieving optimum as well as accurate predictions. Owing to the experimental limitations, head FE modelling remains to be one of the strongest candidate in analysing both the head and brain responses under different loading and boundary conditions to replicate TBI incidents.

Back in 1973, Hardy and Marcal [12] have developed the simplest two-dimensional human head model. They modelled the skull as an ellipse with elastic material properties. Later in 1975, Shugar [13] came up with another 2D model of an elastic brain placed inside a rigid skull. More improvements were seen later where Khalil and Hubbard [14] 
included the scalp and intracranial components in their model. The advancement in the model was continued by Horsey and Liu [15], where they have developed a head model based on the anatomy of the head, which is more anthropometric and utilising different type of material properties. The evolution of the FE head models is seen until today with the advancement of computer hardware and with the increase of computing power. Many complicated FE head models have been developed from time to time [4, 16-19]. The more recent models have even utilised the computed tomography (CT) images as well as the magnetic resonance imaging (MRI) technique to produce even more biofidelic FE head model that closely resembles an actual human head together with all components inside the head [4].

These sophisticated models definitely requires high computation power. Therefore, the aim of this study is to propose a relatively simple 3D FE head model that is validated against a blunt impact experiment of Nahum et al. [6]. This study also investigates the claim made by Ruan et. al. and Willinger et. al. [20, 21] that the neck does not significantly influence the brain responses by varying the neck boundary conditions. Our simulation results were then compared to a number of existing complex models $[4,18,19,22]$ to assess its validity.

\section{MODEL DEVELOPMENT}

This study proposes a relatively less complicated human head FE model. The skull comprises of the cranium and the facial bones as two separate sections. Both the cranium and facial bones were defined as linear elastic with an modulus of elasticity of $6.5 \mathrm{GPa}$ and Poisson's ratio of 0.2 . The density of the cranium and the facial bones were defined as 2,070 $\mathrm{kg} / \mathrm{m}^{3}$ and $5,000 \mathrm{~kg} / \mathrm{m}^{3}$, respectively [23].

Underneath the cranium, we generated a layer of the cerebrospinal fluid (CSF) from the inner surface of the cranium with a thickness of $1.3 \mathrm{~mm}$. The CSF sits in between the skull and the brain. It absorbs shock applied to the head [24] to protect the brain from closed head impacts [25]. The CSF has been modelled using various material definitions such as elastic material with fluid-like properties, viscoelastic material and nearly incompressible elastic material [24]. However, the simplest way and has been defined in many models is by defining the CSF as a nearly incompressible elastic material. In our model, the CSF was modelled as linear elastic (modulus of elasticity of $150 \mathrm{kPa}$ and Poisson's ratio of 0.49886 ) [26], with a density of $1,004 \mathrm{~kg} / \mathrm{m}^{3}$.

The solid brain, on the other hand, fills the area underneath the CSF. Unlike the skull and CSF, the brain was defined as viscoelastic, with a linear elastic material model. This requires the value of modulus of elasticity, $E$, which was determined using the following equation [20]:

$$
E=\frac{9 K G}{3 K+G}
$$

where $K$ is the bulk modulus and $G$ is the shear modulus. The value of $E$ obtained was $5.04 \mathrm{MPa}$. The Poisson's ratio of the brain was defined as 0.4996 [20]. The brain has a density of $1,040 \mathrm{~kg} / \mathrm{m}^{3}$, which produces a mass of $1.56 \mathrm{~kg}$. The shear attributes of the viscoelasticity of the brain were given by:

$$
G(t)=G_{\infty}+\left(G_{0}-G_{\infty}\right) e^{-\beta t}
$$

where $G_{0}$ is the short-term shear modulus $(0.528 \mathrm{MPa}), G_{\infty}$ is the long-term shear modulus $(0.168 \mathrm{MPa}), \beta$ is the decay factor that was defined as $35 \mathrm{~s}^{-1}$ and $t$ is time, expressed in second [27]. These characteristics were implemented in ABAQUS 6.13 as the time domain viscoelastic material model that is given by a Prony series expansion of the following dimensionless relaxation modulus [28]:

$$
g_{R}(t)=1-\bar{g}^{P}\left(1-e^{-t / \tau^{G}}\right)
$$

where $\bar{g}^{P}=\left(G_{0}-G_{\infty}\right) / G_{0}$ and $\tau^{G}=1 / \beta$ [29]. The developed FE head model comprises of four components, namely the brain, CSF, cranium and facial bones, and it weighs $3.45 \mathrm{~kg}$. The mass is about $1 \mathrm{~kg}$ less than the 50th percentile human head mass of $4.55 \mathrm{~kg}$ [30]. This is attributed to the lack of several features such as the scalp and some parts of the facial bones that were not modelled. Table 1 shows the summary of the elastic properties of individual components in our model while Figure 1 shows the head model and its distinctive sections.

Table 1. Elastic properties of every component in the head model.

\begin{tabular}{ccccc}
\hline Component & $\begin{array}{c}\text { Density } \\
\left(\mathbf{k g} / \mathbf{m}^{\mathbf{3}}\right)\end{array}$ & $\begin{array}{c}\text { Modulus of elasticity } \\
(\mathbf{M P a})\end{array}$ & Poisson's ratio & Reference \\
\hline Skull & 2,070 & 6,500 & 0.2 & {$[23]$} \\
Facial bones & 5,000 & 6,500 & 0.2 & {$[23]$} \\
CSF & 1,004 & 0.15 & 0.49886 & {$[26]$} \\
Brain & 1,040 & 5.04 & 0.4996 & {$[20]$} \\
\hline
\end{tabular}




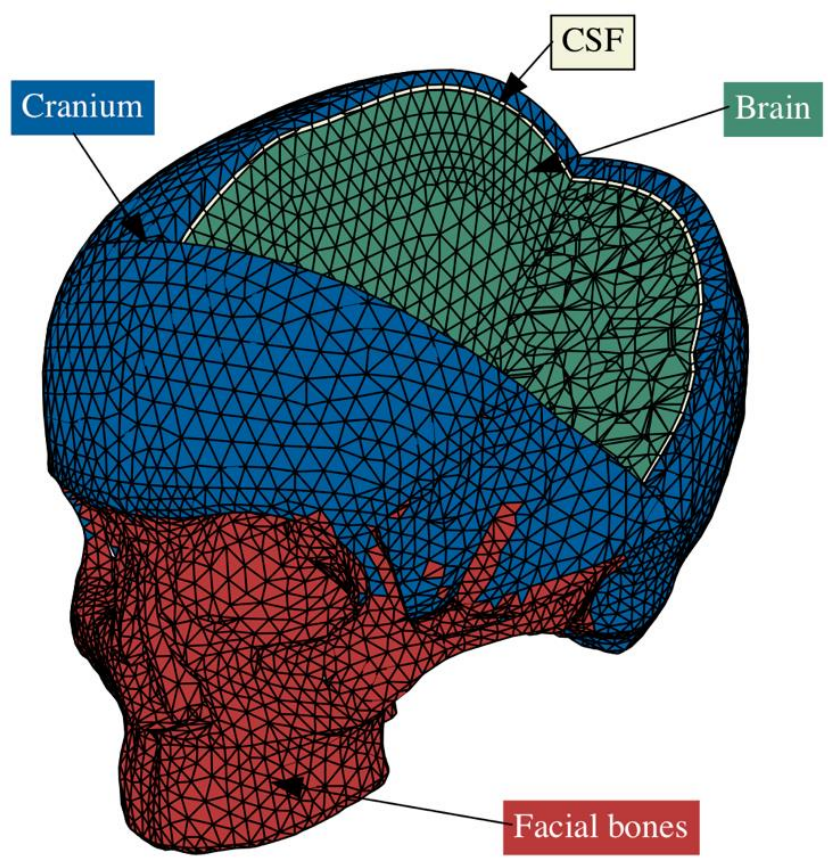

Figure 1. The developed FE head model.

The skull-brain interface has been defined using either tied nodes, sliding interface or solid CSF model. Ganpule [31] cited that tied interface gave the best results compared with the experimental data. Thus, we have modelled the CSF as solid and applied the tie constraint properties between the inner surface of the cranium and the outer surface of the CSF, as well as the inner surface of the CSF and the outer surface of the brain.

The boundary condition at the head-neck joint is among the focus of this study. [20] and [21] have demonstrated that the effect of the neck is negligible for short duration impacts. Modelling the neck as a series of springs and dampers has also been done to study its impact on the brain response [32]. Thus, we have decided to perform a parametric study by simulating the head-neck boundary condition under three circumstances: free boundary condition (no constraint at the head-neck joint), fixed boundary condition, and modelling the neck as a series of springs and dampers. In the fixed boundary condition, the nodes around the foramen magnum were fully constrained, allowing no displacement or rotation. With regards to the neck modelled as a series of springs and dampers, a group of nine springs and dampers with length ranging from 80 to $100 \mathrm{~mm}$ were arranged in a circular form and connected in parallel to the head [32]. The other end of the springs and dampers were connected to a circular geometry of a diameter of $80 \mathrm{~mm}$, assumed as the torso, which was fully constrained. The overall stiffness of the springs is $1,800 \mathrm{kN} / \mathrm{m}$ while the overall damping coefficient of the dampers is $450 \mathrm{Ns} / \mathrm{m}$ [32]. Figure 2 shows the head-neck boundary conditions.

(a)

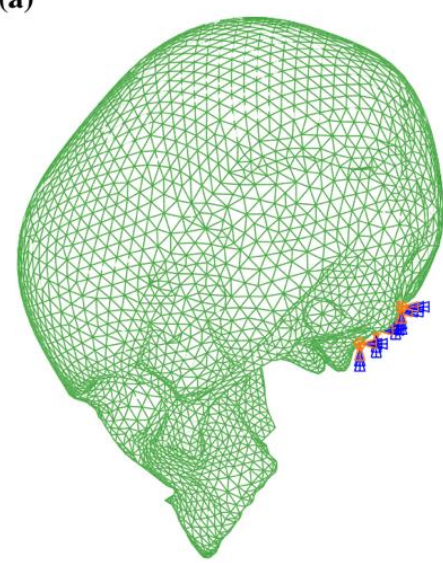

(b)

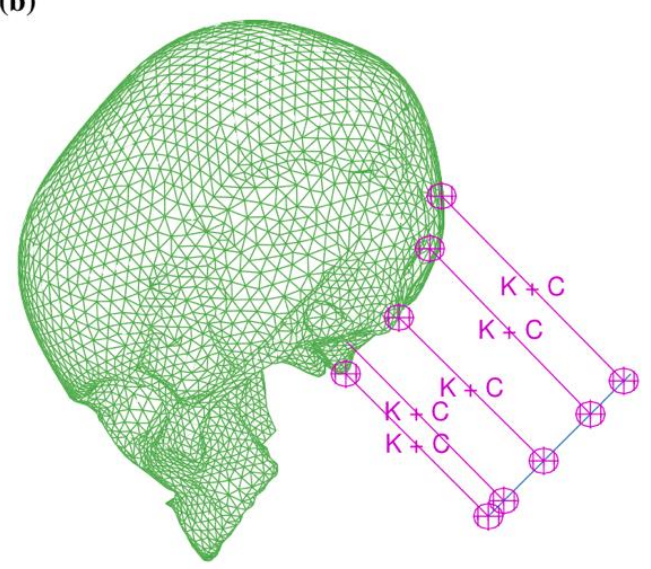

Figure 2. Head-neck boundary condition: (a) fixed boundary condition and (b) spring-damper neck 


\section{MODEL VALIDATION}

The experiment conducted by Nahum and colleagues [5, 6] back in 1971 has been the main reference data to validate human head finite element models. They performed a head impact experiment on a seated human cadaver. The forehead of the cadaver was hit by a rigid padded mass. Intracranial pressured were measured at five locations (in the frontal bone adjacent to the impact contact area, immediately posterior and superior to the coronal and squamosal sutures respectively in the parietal bone, inferior to the lambdoidal suture in the occipital bone (one on each side) and in the occipital bone at the posterior fossa) by means of pressure transducers.

To validate our model, we have simulated Nahum's experiment 37 due to the availability of its data. However, we did not impact the skull with the rigid mass as per Nahum's experiment, but we decided to apply the pressure resulted by the impact on the forehead instead. We believe that this approach reduces the computational complexity and cost significantly. The impact force was extracted from Nahum's data as shown in Figure 3(a) and it was applied within an area of $1,630 \mathrm{~mm}^{2}$ on the frontal bone of the skull as shown in Figure 3(b).

(b)
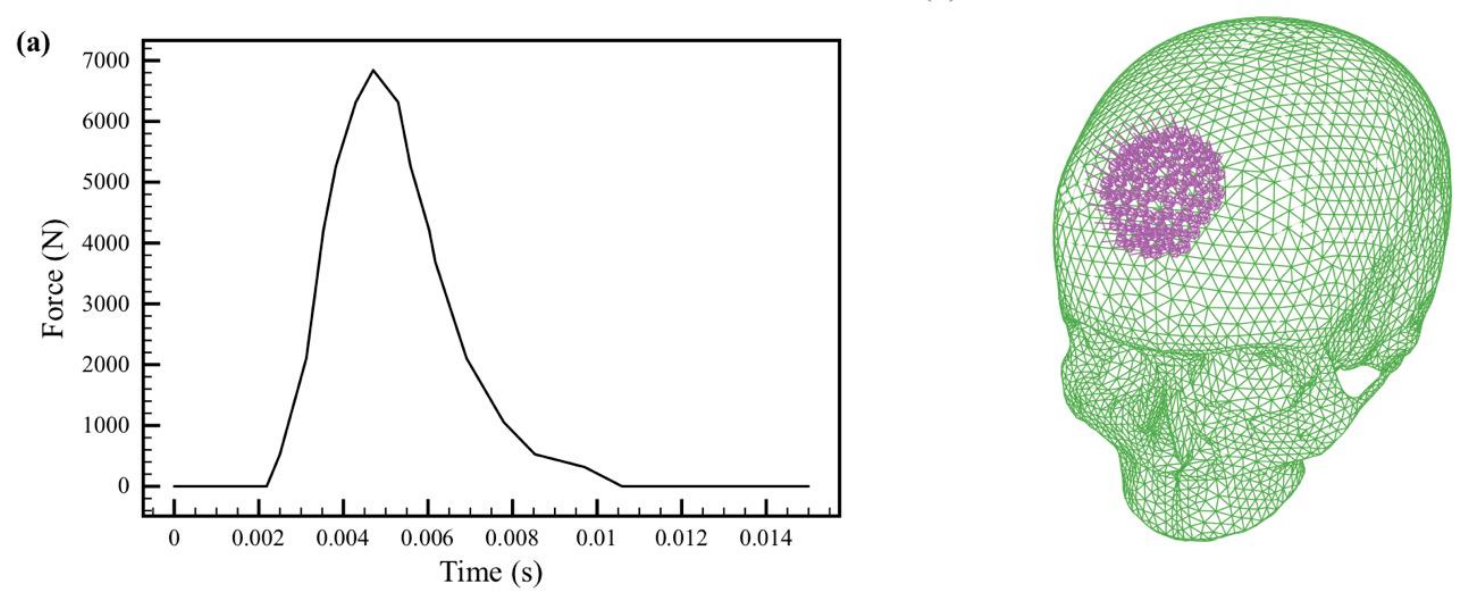

Figure 3. (a) The impact force extracted from Nahum's experiment and (b) pressure applied to the frontal bone, the Frankfort horizontal plane was inclined by $45^{\circ}$.

To validate our model against Nahum's data, intracranial pressures at the previously mentioned locations and the head acceleration induced by the impact were compared. Intracranial pressure, $p$ is the average of the principal stresses that were obtained from the simulation [20, 27]. It was calculated as follows:

$$
p=\frac{1}{3}\left(\sigma_{1}+\sigma_{2}+\sigma_{3}\right)
$$

The head acceleration measured in Nahum's experiment is assumed as the acceleration of the centre of gravity of the head. The measurement of acceleration directly at the centre of gravity of the head in our model is not possible due to the unavailability of a node. Thus, we have selected a node on the sagittal plane of the skull at which the acceleration outputs were requested. The acceleration of the centre of gravity of the head can be determined using the following rigid body dynamics equation:

$$
\vec{a}_{c g}=\vec{a}_{\text {node }}+\vec{\alpha} \times \vec{r}+\vec{\omega} \times(\vec{\omega} \times \vec{r})
$$

The locations where intracranial pressures were measured in Nahum's experiment, although being stated in their paper [6], were not clearly shown. We have estimated the locations of the pressure measurement according to what have been described. The intracranial pressures were measured from the CSF layer instead of the brain, similar to what was done by Nahum and colleagues. Figure 4 shows the locations of elements, in which the pressure responses were measured, and the location of the node where both translational and rotational acceleration were requested. 
(a)

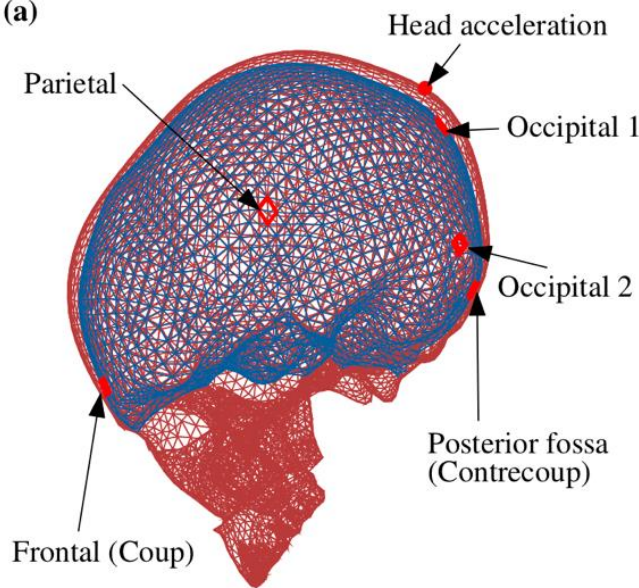

(b)

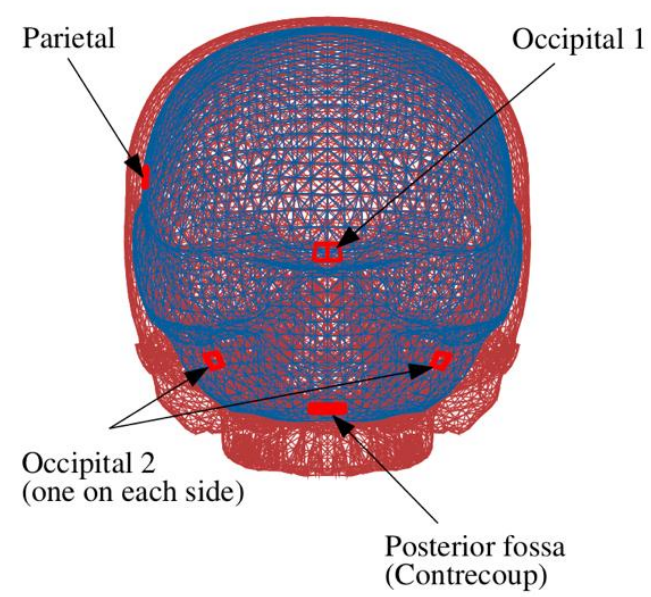

Figure 4. The locations of the intracranial pressures and head acceleration measurement.

The analysis was performed for a period of $15 \mathrm{~ms}$ with a time step of $0.2 \mathrm{~ms}$ using a personal computer running on standard quad core processor with a speed of $2.40 \mathrm{GHz}$ and a memory of $8 \mathrm{~GB}$. A low-pass, second order, Butterworth filter with a cut-off frequency of one-sixth of the output sample rate $(5,000 / 6=833.3 \mathrm{~Hz})$, a value lower than the Nyquist frequency of the one-half the sample rate, was applied in the post processing operation. This was done instead of realtime filtering to avoid the output data from suffering the time delay [28].

\section{RESULTS AND DISCUSSION}

We have simulated Nahum's experiment 37 [6] to validate our human head FE model. The impact force from Nahum's experiment was applied on the frontal bone of the skull. Three head-neck boundary conditions were simulated to investigate their impact on the brain response. Our results were compared with intracranial pressure data at several locations: at the frontal bone (coup pressure), at the posterior fossa (contrecoup pressure), two locations at the occipital bone and at the parietal bone. Furthermore, the head acceleration of our model was also compared with Nahum's experimental data. Figure 5 shows the comparison between Nahum's experimental data and our simulation for all headneck boundary conditions.

Prior to the analysis, we hypothesised that head-neck boundary condition will have an influence on the brain response. Our results have demonstrated that this hypothesis is true. It is apparent that different responses were recorded for each condition as shown in Figure 5. In comparison with Nahum's data, we found that the free head-neck boundary condition has produced responses that agree very well with the experimental data. Our results might be justified by the fact that Nahum and colleagues have performed the experiments on human cadaver, which suggests that the neck muscle might not play any role during the experiment. Thus, the responses recorded match those generated by our model for free headneck boundary condition. The fixed boundary condition and the spring-damper neck, however, have overestimated the intracranial pressure responses in our simulation. [21] and [20] have reported that the neck has no influence on the brain response for short duration impact (less than 6 milliseconds), conversely our simulation suggests otherwise. The influence and the mechanics of the head-neck boundary condition on the brain response should be further studied. 

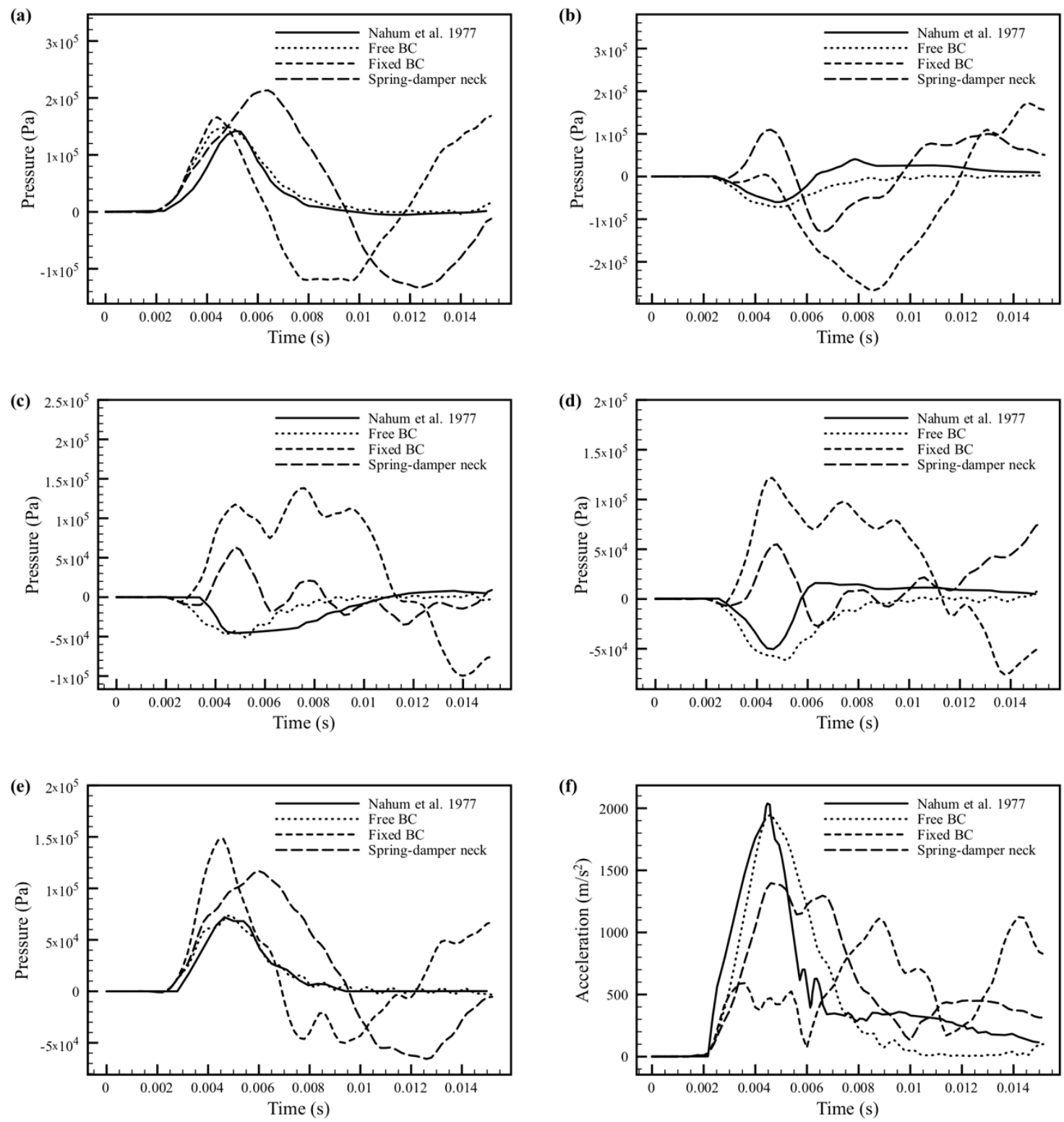

Figure 5. Time histories of intracranial pressures and head acceleration: (a) Frontal (coup) pressure, (b) Posterior fossa (contrecoup) pressure, (c) Occipital 1 pressure, (d) Occipital 2 pressure, (e) Parietal pressure and (f) Head acceleration.

As the goal of this study was to develop a human head model with low computational cost, we have measured the computing time for each head-neck boundary condition as presented in Table 2.

Table 2. The computing time for each head-neck boundary condition.

\begin{tabular}{cc}
\hline Head-neck boundary condition & Computing time (min.) \\
\hline Free boundary condition & 15.97 \\
Fixed boundary condition & 14.89 \\
Spring-damper neck & 57.06 \\
\hline
\end{tabular}


Table 3. Comparison of head model geometries and the behaviour of each geometry.

\begin{tabular}{|c|c|c|}
\hline Model & Components & Behaviour \\
\hline Our model & $\begin{array}{l}\text { Skull } \\
\text { Facial bones } \\
\text { Cerebrospinal fluid (CSF) } \\
\text { Brain }\end{array}$ & $\begin{array}{l}\text { Elastic } \\
\text { Elastic } \\
\text { Elastic } \\
\text { Viscoelastic }\end{array}$ \\
\hline $\begin{array}{l}\text { Willinger et al. } 1999 \\
\text { [22] }\end{array}$ & $\begin{array}{l}\text { Skull } \\
\text { Facial bones } \\
\text { Subarachnoid space (dura, CSF, arachnoid) } \\
\text { Brain } \\
\text { Tentorium and falx }\end{array}$ & $\begin{array}{l}\text { Elastic } \\
\text { Elastic } \\
\text { Elastic } \\
\text { Viscoelastic } \\
\text { Elastic }\end{array}$ \\
\hline $\begin{array}{l}\text { Horgan and Gilchrist } \\
2003 \text { [19] }\end{array}$ & $\begin{array}{l}\text { Scalp } \\
\text { Cortical bone } \\
\text { Trabecular bone } \\
\text { Dura } \\
\text { Pia } \\
\text { Falx and tentorium } \\
\text { Brain } \\
\text { Facial bone }\end{array}$ & $\begin{array}{l}\text { Elastic } \\
\text { Elastic } \\
\text { Elastic } \\
\text { Elastic } \\
\text { Elastic } \\
\text { Elastic } \\
\text { Hyperelastic } \\
\text { Elastic }\end{array}$ \\
\hline Kleiven 2006 [18] & $\begin{array}{l}\text { Outer table/face } \\
\text { Inner table } \\
\text { Diploe } \\
\text { Neck bone } \\
\text { Brain } \\
\text { Cerebrospinal fluid (CSF) } \\
\text { Sinuses } \\
\text { Dura mater } \\
\text { Falx/tentorium } \\
\text { Pia mater } \\
\text { Scalp } \\
\text { Bridging veins }\end{array}$ & $\begin{array}{l}\text { Elastic } \\
\text { Elastic } \\
\text { Elastic } \\
\text { Elastic } \\
\text { Hyper-/Viscoelastic } \\
\text { Elastic } \\
\text { Elastic } \\
\text { Elastic } \\
\text { Elastic } \\
\text { Elastic } \\
\text { Elastic } \\
\text { Elastic }\end{array}$ \\
\hline Yang et al. 2014 [4] & $\begin{array}{l}\text { Brainstem } \\
\text { Cerebral peduncle } \\
\text { Cerebellum } \\
\text { Cerebrospinal fluid (CSF) } \\
\text { Gray matter } \\
\text { Lateral cartilage } \\
\text { Septum cartilage } \\
\text { Skull bone and cervical vertebra } \\
\text { Neck and facial soft tissue } \\
\text { Ventricles } \\
\text { White matter }\end{array}$ & $\begin{array}{l}\text { Viscoelastic } \\
\text { Viscoelastic } \\
\text { Viscoelastic } \\
\text { Fluid } \\
\text { Viscoelastic } \\
\text { Elastic } \\
\text { Elastic } \\
\text { Elastic } \\
\text { Elastic } \\
\text { Viscoelastic } \\
\text { Viscoelastic }\end{array}$ \\
\hline
\end{tabular}

The simulation for free boundary condition, which has produced the best agreement with experimental data, was computed in 15.97 minutes. Fully constraining the head was seen to have almost negligible effect on the computing time. Incorporating spring and dampers as neck, however, has increased the complexity of the model, thus resulting in a computing time of 57.06 minutes, an increase of approximately $257 \%$ compared with the computing time for the free boundary condition model. The computing time shown in Table 2 is based on simulation done on a personal computer. This shows that our model is not only capable of producing brain responses that are in a good agreement with experimental data of human cadaver, but also does not require high computational cost. 

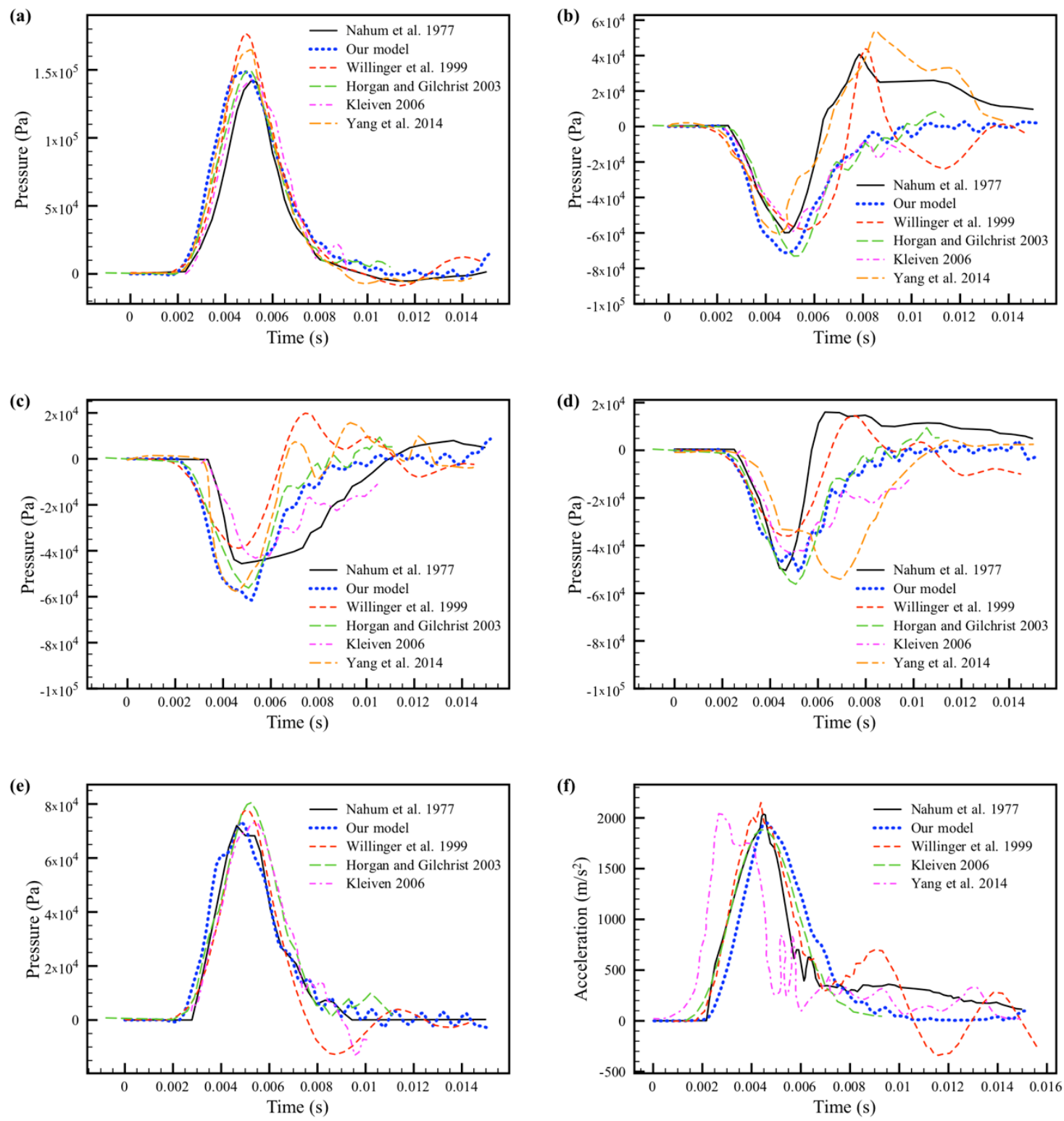

Figure 6. Comparison of results generated by our model and other head models: (a) Frontal (coup) pressure, (b) Posterior fossa (contrecoup) pressure, (c) Occipital 1 pressure, (d) Occipital 2 pressure, (e) Parietal pressure and (f) Head acceleration.

To further evaluate the validity of our model in predicting brain responses during impact, we have compared the results generated by our model with those of several head models: $[4,18,19,22]$. These head models contain a lot more individual components as compared to ours, thus increase the complexity and computational cost. Table 3 shows the list of components and their respective material behaviour of the head models. Intracranial pressures and head acceleration predicted by these models for Nahum's experiment 37 are shown in Figure 6.

It is observed from Table 3 that our simplified head model consists of only four components, whereas other head models comprises of five components or more. This shows the simplicity of the present model as compared to other published models. As stated previously, one of the objectives of this study is to investigate the prediction accuracy of our simplified head model. In simulating a complex head impact scenario, a simplified model is preferred due to its low computational cost. Thus, we have compared the predictions of our simplified head model based on Nahum's experimental data [6].

Figure 6 shows the comparison of intracranial pressures and head accelerations generated by our model with those of other head models. The intracranial pressures at five different locations were compared: frontal, posterior fossa, occipital, and parietal, in addition to the head acceleration. It is observed that the results generated by our model are comparable to other models that are more complicated in terms of geometry and material definition. In some cases, our model has produced better correlation with Nahum's experimental data compared with other models. This gave us more confidence in using our model for further analysis of head impacts. 


\section{CONCLUSIONS}

A relatively simple FE head model was proposed to investigate the brain responses during head impact. The goal of this paper was to produce a model with low computational cost without compromising its capability in predicting brain responses during impact. The most inner part of the developed model is the brain, which is wrapped by a layer of cerebrospinal fluid. The outermost part of the model is the skull that is comprised of two sections: the cranium and the facial bones. Material properties for each component were obtained from various literatures. Laboratory testing on human cadaver conducted by Nahum and colleagues was simulated to validate our model. Intracranial pressures at several locations and the head accelerations were measured. Three head-neck boundary conditions were analysed to investigate their impact on the brain response. Our simulation showed that the head-neck boundary condition does in fact influence the brain response. The free head-neck boundary condition has duplicated the experimental response reasonably well. The fixed boundary condition and the spring-damper neck were found to have overestimated the intracranial responses as well as the head acceleration. Further works directed on modelling appropriate head-neck joint are needed. It was evident that the incorporation of the springs and dampers as the neck has also increased the computation time by $257 \%$. Our model with free boundary condition was compared with responses generated by other head models. We found that our model is capable of generating comparable brain responses to those of more complicated model. This establishes the fact that a simplified model like ours is not only low in computational cost, but also could produce reliable results.

\section{ACKNOWLEDGMENTS}

The authors would like to thank Universiti Malaysia Pahang for providing the simulation facilities and funding for this study under internal grant RDU1803185.

\section{REFERENCES}

[1] S. F. Jamaluddin, M. Abd Wahab, M. Y. Abdul Wahab, Y. T. Ming, and I. Mohd Saiboon, "National Trauma Database January 2009 to December 2009 - Fourth Report, Malaysia," 2011.

[2] G. M. Teasdale, "Head injury.," J. Neurol. Neurosurg. Psychiatry, vol. 58, no. 5, pp. 526-539, May 1995.

[3] K. L. Monson, "Mechanical and failure properties of human cerebral blood vessels," University of California, Berkeley, 2001.

[4] B. Yang et al., "Development of a finite element head model for the study of impact head injury.," Biomed Res. Int., vol. 2014, pp. 1-14, Jan. 2014, doi: 10.1155/2014/408278.

[5] A. M. Nahum and R. W. Smith, “An Experimental Model for Closed Head Impact Injury.” SAE International, 1976.

[6] A. M. Nahum, R. Smith, and C. C. Ward, "Intracranial Pressure Dynamics During Head Impact.” SAE International, 1977.

[7] X. Trosseille, C. Tarriére, F. Lavaste, F. Guillon, and A. Domont, "Development of a F.E.M. of the Human Head According to a Specific Test Protocol." SAE International, 1992, doi: 10.4271/922527.

[8] W. N. Hardy, "Response to the Human Cadaver Head to Impact," Wayne State University, 2007.

[9] P. E. Riches, "A dynamic model of the head acceleration associated with heading a soccer ball," Sport. Eng., vol. 9, no. 1, pp. 39-47, Mar. 2006, doi: 10.1007/BF02844261.

[10] C. F. Babbs, "Biomechanics of heading a soccer ball: implications for player safety.," Sci. World J., vol. 1, pp. 281-322, Aug. 2001, doi: 10.1100/tsw.2001.56.

[11] Z. Taha, M. H. A. Hassan, and I. Hasanuddin, "Analytical modelling of soccer heading," Sadhana, vol. 40, no. 5, pp. 15671578, 2015, doi: 10.1007/s12046-015-0383-5.

[12] C. H. Hardy and P. V Marcal, "Elastic Analysis of a Skull,” J. Appl. Mech., vol. 40, no. 4, pp. 838-842, Dec. 1973.

[13] T. A. Shugar, "Transient Structural Response of the Linear Skull-Brain System," SAE Tech. Pap. 751161, 1975, doi: $10.4271 / 751161$.

[14] T. B. Khalil and R. P. Hubbard, "Parametric study of head response by finite element modeling," J. Biomech., vol. 10, no. 2, pp. 119-132, 1977, doi: http://dx.doi.org/10.1016/0021-9290(77)90075-6.

[15] R. R. Horsey and Y. K. Liu, "A homeomorphic finite element model of the human head and neck," in Finite Elements in Biomechanics, 1981, pp. 379-401.

[16] S. Ji, W. Zhao, Z. Li, and T. W. McAllister, "Head impact accelerations for brain strain-related responses in contact sports: a model-based investigation.," Biomech. Model. Mechanobiol., vol. 13, no. 5, pp. 1121-1136, Oct. 2014, doi: 10.1007/s10237014-0562-z.

[17] R. J. H. Cloots, J. a W. van Dommelen, S. Kleiven, and M. G. D. Geers, "Multi-scale mechanics of traumatic brain injury: predicting axonal strains from head loads.," Biomech. Model. Mechanobiol., vol. 12, no. 1, pp. 137-150, Jan. 2013, doi: 10.1007/s10237-012-0387-6.

[18] S. Kleiven, "Evaluation of head injury criteria using a finite element model validated against experiments on localized brain motion, intracerebral acceleration, and intracranial pressure," Int. J. Crashworthiness, vol. 11, no. 1, pp. 65-79, Jan. 2006, doi: 10.1533/ijcr.2005.0384. 
[19] T. J. Horgan and M. D. Gilchrist, "The creation of three-dimensional finite element models for simulating head impact biomechanics," Int. J. Crashworthiness, vol. 8, no. 4, pp. 353-366, 2003, doi: 10.1533/ijcr.2003.0243.

[20] J. S. Ruan, T. Khalil, and A. I. King, "Dynamic response of the human head to impact by three-dimensional finite element analysis.," J. Biomech. Eng., vol. 116, no. 1, pp. 44-50, Feb. 1994.

[21] R. Willinger, L. Taleb, and C.-M. Kopp, "Modal and Temporal Analysis of Head Mathematical Models," J. Neurotrauma, vol. 12, no. 4, pp. 743-754, Aug. 1995.

[22] R. Willinger, H.-S. Kang, and B. Diaw, "Three-Dimensional Human Head Finite-Element Model Validation Against Two Experimental Impacts,” Ann. Biomed. Eng., vol. 27, no. 3, pp. 403-410, 1999, doi: 10.1114/1.165.

[23] M. Claessens, "Finite Element Modeling of the Human Head under Impact Conditions," Eindhoven University of Technology, 1997.

[24] M. S. Chafi, V. Dirisala, G. Karami, and M. Ziejewski, "A finite element method parametric study of the dynamic response of the human brain with different cerebrospinal fluid constitutive properties," Proc. Inst. Mech. Eng. Part H J. Eng. Med., vol. 223, no. 8, pp. 1003-1019, Nov. 2009.

[25] Y. Luo, Z. Li, and H. Chen, "Finite-element study of cerebrospinal fluid in mitigating closed head injuries," Proc. Inst. Mech. Eng. Part H J. Eng. Med., vol. 226, no. 7, pp. 499-509, May 2012, doi: 10.1177/0954411912445729.

[26] Y. Chen and M. Ostoja-Starzewski, "MRI-based finite element modeling of head trauma: spherically focusing shear waves," Acta Mech., vol. 213, no. 1-2, pp. 155-167, Feb. 2010.

[27] J. S. Ruan, T. B. Khalil, and A. I. King, "Finite element modeling of direct head impact," in Stapp Car Crash Conference, 1993.

[28] Dassault Systèmes, "Abaqus 6.13 Documentation.” 2013.

[29] S. P. C. Marques and G. J. Creus, "Solution with Abaqus," in Computational Viscoelasticity, Berlin, Heidelberg: Springer Berlin Heidelberg, 2012, pp. 103-111.

[30] R. S. J. M. Verhoeve, “A Computer Model of the Human Head to Assess Mechanical Brain Loading in Car Collisions,” 1999.

[31] S. G. Ganpule, "Mechanics of blast loading on post-mortem human and surrogate heads in the study of Traumatic Brain Injury (TBI) using experimental and computational approaches," 2013.

[32] V. Dirisala, G. Karami, and M. Ziejewski, "Effects of neck damping properties on brain response under impact loading," Int. j. numer. method. biomed. eng., vol. 28, no. November 2011, pp. 472-494, 2012, doi: 10.1002/cnm. 